\title{
Efficiency of rice farms and its determinants: application of stochastic frontier analysis
}

\begin{abstract}
In the context to achieve the self sufficiency in rice production at $75 \%$ of local consumption, Malaysian authority consistently encourages the increase of rice production by the improvement of the yield through the utilization of the optimal input used, new technology and farm management. However, these efforts is hampered by the low productivity which is caused mainly by the inefficient used of input and subsequently affects the production inefficiency as well. Hence, in order to address those problems, this study aims to measure the production and subtitution elasticity, the existing level of rice farm efficiency and determinants of the efficiency using the stochastic frontier analysis. Out of five inputs, land, seed and chemical significantly influence the rice farms in MADA, Malaysia. Further, since the rice farms operated at the increasing return to scale, there was a possibility to increase the production by improving the input use. On average, the sampled farms in this study had the tecnical efficiency at 0.854 and implied those rice farms still could increase its output about $14.6 \%$ at a given inputs. The farmer's access to credit and their education level were the important determinant upon the rice farms technical efficiency.
\end{abstract}

Keyword: Technical efficiency; Elasticity; Inefficient model; Rice farms 